Conclusion Upon department discussion it was agreed to introduce a safety pause, read-back and an ISBAR system to optimise time, patient safety and communication. Punctual attendance was stressed, as was up to date information being assigned to the ward clerk in the morning.

\section{P154 IMPROVING THE HAEMOGLOBINOPATHY SCREENING PROGRAMME FOR HIGH-RISK PATIENTS IN A TERTIARY MATERNITY HOSPITAL IN DUBLIN, A PILOT QUALITY IMPROVEMENT INITIATIVE}

${ }^{1}$ Jennifer Finnegan*, 'John David Corcoran, ${ }^{2}$ McMahon Corrina. ${ }^{1}$ Rotunda Hospital, Dublin, Ireland; ' ${ }^{2}$ ur Lady's Children's Hospital Crumlin, Dublin, Ireland

\subsection{6/archdischild-2019-epa.509}

Introduction A more coordinated haemoglobinopathy screening is desired across European countries $_{1}$. A non-funded pilot screening programme was implemented in six Irish maternity units in $2005_{2}$. It aims to identify patients with haemoglobinopathies such as sickle cell disease and thalassemia, by screening patients from high-risk ethnic origins.

As screening involves identifying disease carriers, ensuring informed consent is vital. Since the introduction of an electronic healthcare record in the Rotunda hospital in November 2017, patients no longer sign consent forms before blood samples are taken. Attendance rates at haematology clinics are poor, it is proposed that this is due to lack of education about screening and lack of early contact with results $_{2}$.

Aim To ensure appropriate information sharing between laboratories.

To ensure parents are fully informed of the benefits of screening and that their consent to testing is recorded.

To ensure correspondence is sent to all families informing them of positive test results and arranging a follow up appointment with haematology.

To establish a successful pilot programme that can be expanded to all other maternity units.

Methods A cross-hospital working group was established. Following a literature review, the HSE Change Model was used as an organisational development model $_{2}$. An information leaflet, a consent form and a letter informing parents of abnormal results were developed. A standard Operating Procedure was agreed which outlines how screening will proceed uniformly across all hospitals.

Further Steps These improvement initiatives are being implemented in the Rotunda.

An organisational development approach is used to ensure that consent is obtained and positive test results are acted upon. Rates of attendance at haematology OPD will be reviewed following implementation of changes.

Following successful implementation, the initiative will be replicated in the other pilot hospitals and ultimately in all maternity hospitals in Ireland.

\section{REFERENCES}

1. Lobitz S, Telfer P, Cela E, Allaf B, Angastiniotis M, Backman Johansson C, Badens C, Bento C, Bouva MJ, Canatan D, Charlton M. Newborn screening for sickle cell disease in Europe: recommendations from a Pan-European Consensus Conference. British journal of haematology. 2018 Nov; 183(4):648-60.

2. Gibbons C, Geoghegan R, Conroy H, Lippacott S, O'Brien D, Lynam P, Langabeer L, Cotter M, Smith O, McMahon C. Sickle cell disease: time for a targeted neonatal screening programme. Irish medical journal. 2015 Feb 1.

\section{P155 \\ IMPROVING PATIENT SAFETY IN A TERTIARY CENTRE THROUGH THE INTRODUCTION OF A STANDARDISED ADMISSION DOCUMENT FOR PAEDIATRIC PATIENTS}

Sarah Murphy*, Lesley Nairn, Fiona Hillis. Royal Hospital For Children, Glasgow, UK

10.1136/archdischild-2019-epa.510

Background There was a lack of unifomity in the initial medical admission documentation for patients admitted under general paediatrics at the Royal Hospital for Children, Glasgow. There was no standardised medical admission document used for admitting patients. Thus significant variability was seen in terms of quality of initial medical admission documentation and crucial elements of the paediatric history were frequently omitted. A method of improving and standardising care through improving documentation was sought.

Objective To enhance patient safety through improved documentation of admissions under general paediatrics. A standardised admissions document was introduced with the aim of reducing medication omissions, improving medication reconciliation and standardising documentation, to include all crucial elements of the paediatric history in one document.

Methods A standardised admissions document was created and introduced using the Plan Do Study Act (PDSA) Cycle ${ }^{1}$.The document included all essential compenents of the padiatric history. Six essential criteria were identified for inclusion in the initial paediatric admission documentation. These included: Medication reconciliation, Social work involvement, Smoking in the household, Immunisation history, Birth History and Developmental History. The admission document was intended to be used by all junior paediatric and GP trainees in the clinical decisions unit for the admission of all patients under general paediatrics.

The notes of 40 patients pre-intervention and 40 patients post-intervention were reviewed. The notes were reviewed for documentation of the 6 essential criteria as defined above.

Results Significant improvements were seen across all domains after the introduction of the admission document. A marked improvement in medication documentation was noted postIntervention. Complete documentation of medications rose from $45 \%$ pre-intervention, to $75 \%$ post intervention. Immunisation history documentation improved from $55 \%$ to $87.5 \%$. Birth history documentation improved from $60 \%$ pre-intervention to $87.5 \%$ post intervention. The most significant improvements were observed in documentation of Social work involvement (15\% pre-intervention to $82.5 \%$ post-intervention), Developmental history $(22.5 \%$ pre-intervention to $95 \%$ post-intervention) and Household smoking history documentation $(22.5 \%$ pre-intervention to $85 \%$ postintervention).

Conclusion The introduction of a standardised admissions document is a simple tool by which to improve care and standardise documentation of all paediatric admissions. Having a specific admissions document is shown to improve patient safety by reducing medication omissions by implementing medication reconcilation in the admissions document. A standardised document allows for a focused paediatric history encompassing all essential domains to be obtained for every child on their initial admission to the department,thereby reducing omissions of important medical information. 